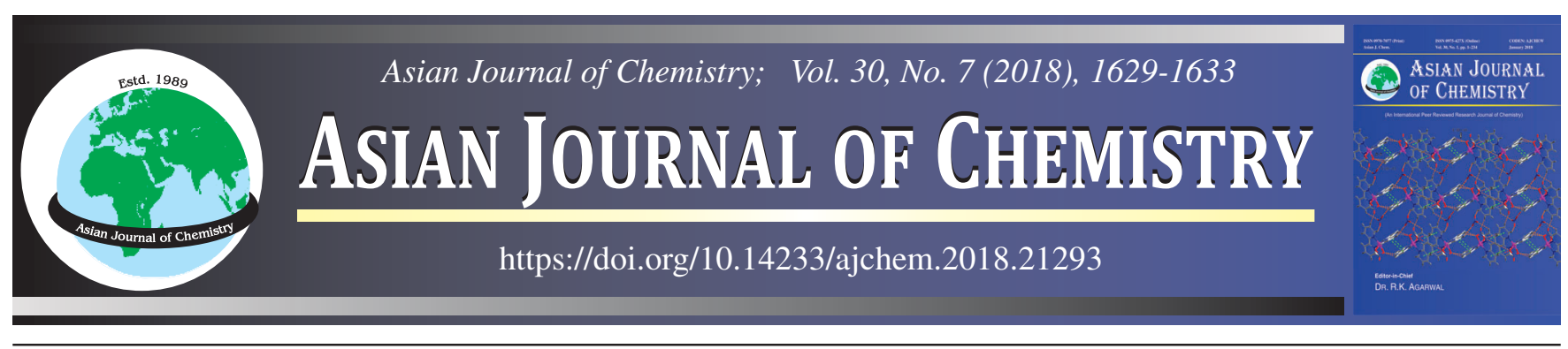

\title{
Corrosion Inhibition of Mild Steel by Capacitabine in Hydrochloric Acid Medium
}

\author{
A.M. GURUPRASAD ${ }^{1}$, H.P. SACHIN ${ }^{2, *}$ and G.A. SWETHA ${ }^{3}$
}

${ }^{1}$ Department of Chemistry, Mangalore Institute of Technology and Engineering, Moodabidre, Mangalore-574 225, India

${ }^{2}$ Department of Chemistry, Jawaharlal Nehru National College of Engineering, Shivamogga-577 204, India

${ }^{3}$ Department of Chemistry, BMS Institute of Technology, Avalahalli, Yelahanka, Bangalore-560 064, India

*Corresponding author: E-mail: drhps@jnnce.ac.in

Received: 19 February 2018;

Accepted: 21 April 2018;

Published online: 31 May 2018;

AJC-18944

\begin{abstract}
Corrosion inhibition effect of capacitabine (an anticancer agent) on mild steel was carried out in $1 \mathrm{M} \mathrm{HCl} \mathrm{media} \mathrm{by} \mathrm{potentiodynamic}$ polarization, weight loss and electrochemical impedance spectroscopy (EIS) techniques at different temperatures. It has been observed that the inhibition efficiency increased with increase in the concentration of inhibitor and decreased with raise in temperature. Polarization studies shows that the inhibitor acts as mixed type and influence both anodic and cathodic reactions. Similar order of inhibition is observed in weight loss, polarization and electrochemical impedance spectroscopic studies. Inhibitor worked by the phenomenon of adsorption and fits well with Langmuir adsorption isotherm. SEM results revealed the protection of mild steel surface in the presence of capacitabine in the aggressive media.
\end{abstract}

Keywords: Capacitabine, Corrosion, Mild Steel, Adsorption.

ᄂ - - - - - - - - - - - - - - - - - - - - - - - - - - - -

\section{INTRODUCTION}

Mild steel is an important alloy of iron. Though mild steel is susceptible to corrosion mainly in acid media but because of its cost and mechanical properties it is widely used in structural and industrial applications. Pickling is the technique used to remove the formed rust and scale on mild steel in most of the industries especially by the use of hydrochloric acid solution. Minimization of corrosion of steel by the electrochemical reaction with hydrochloric acid is major problems faced in most of the industries especially in petrochemical industries. Even though several methods are there to minimize the process, but use of corrosion inhibitor is most consistent and efficient way in aqueous acid media [1-10]. Most of the effective inhibitors used today are organic molecules with hetero atoms like nitrogen, phosphorous, sulphur and/or oxygen [11-18]. The presence of different functional groups, aromaticity and electron density at donor atoms are found to influence adsorption of inhibitor molecules on corroding metal surface $[19,20]$.

Several studies [21] have addressed the influence of heterocyclic organic compound on corrosion inhibition of mild steel in acid solution. Most of the inhibitors are toxic in nature even though they exhibit good inhibition action. Henceforth, in the present work, an attempt is made to use an anticancer drug compound capacitabine, which is used as a chemotherapeutic drug in the treatment of breast cancer, as inhibitor of corrosion for mild steel in $1 \mathrm{M} \mathrm{HCl}$ media. The choice of inhibitor is based on the presence of large number of electron rich hetero groups, which causes greater adsorption of inhibition on the surface of mild steel. The inhibition effect of capacitabine on mild steel in $1 \mathrm{M} \mathrm{HCl}$ is studied by chemical and electrochemical techniques.

\section{EXPERIMENTAL}

Preparation of metallic specimens: Mild steel specimens having compositions $0.04 \% \mathrm{C}, 0.35 \% \mathrm{Mn}, 0.022 \% \mathrm{P}, 0.036$ $\% \mathrm{~S}$ and the remainder being Fe were used. The specimens of dimension $5 \mathrm{~cm} \times 1 \mathrm{~cm} \times 0.1 \mathrm{~cm}$ were used for weight loss studies and sample dimension of $1 \mathrm{~cm} \times 1 \mathrm{~cm}$ (exposed) with a $5 \mathrm{~cm}$ long stem (isolated with araldite resin) were used for polarization and electrochemical impedance methods. The samples were abraded with emery paper of different grades like 220, 480, 800, 1500 and 2000 fallowed by thorough washing with double distilled water then with acetone and finally dried.

Preparation of corrosive medium: The corrosive environment, $1 \mathrm{M}$ solution of $\mathrm{HCl}$ is prepared by diluting $\mathrm{AR}$ grade conc. $\mathrm{HCl}$ solution by using double distilled water. Capacitabine is a white crystalline powder and soluble in alcohol. The required concentration of inhibitor is obtained by adding exact required amount of capacitabine to $1 \mathrm{M} \mathrm{HCl}$ solution using alcohol as solvent. 
Weight loss measurements: The weight loss study is performed on clean mild steel samples. Mild steel samples are weighed before and after immersion in $100 \mathrm{~mL}$ of $1 \mathrm{M} \mathrm{HCl}$ in the absence and presence of different concentration of inhibitor. Experiments were performed in triplicate.

Electrochemical measurements: Electrochemical measurements are performed using CHI608D electrochemical analyzer (USA) at 298 to 328K. The working electrode is mild steel of $1 \mathrm{~cm}^{2}$ exposed area, platinum is an auxiliary electrode and a saturated calomel electrode were used as reference electrodes. Potentiodynamic polarization studies were carried out at a scan rate of $1 \mathrm{mV} \mathrm{s}^{-1}$ in the given potential range. Metal samples were immersed in the corrosive medium for about $2 \mathrm{~h}$ prior to the measurements.

The impedance measurements were carried out in the frequency range of $100 \mathrm{KHz}$ to $1 \mathrm{mHz}$, at the rest potential, by applying $5 \mathrm{mV}$ sine wave $\mathrm{AC}$ voltage. The same cell and system as in the polarization studies were used. The double layer capacitance $\left(\mathrm{C}_{\mathrm{dl}}\right)$ and the charge transfer resistance $\left(\mathrm{R}_{\mathrm{ct}}\right)$ were calculated from Nyquist plots as described elsewhere [22].

\section{RESULTS AND DISCUSSION}

Weight loss measurements: The efficiency of inhibition of capacitabine is experimentally determined at $298 \mathrm{~K}$ by weight loss method. The metal sample was immersed in $1 \mathrm{M}$ $\mathrm{HCl}$ with different inhibitor concentration for duration of $6 \mathrm{~h}$ in a well aerated place. Rate of corrosion is determined using the following equation:

$$
v_{\text {corr }}=\frac{\Delta \mathrm{m}}{\mathrm{ST}}
$$

where $\Delta \mathrm{m}$ is the difference betwen the weight loss in absence of inhibitor $\left(\mathrm{m}_{0}\right)$ and weight loss in presence of inhibitor $\left(\mathrm{m}_{1}\right)$, $\mathrm{S}$ is the surface area and $\mathrm{T}$ is the time of exposure in hours.

The percentage inhibition efficiency $[23,24]$ is calculated by the following relation:

$$
\eta_{\mathrm{w}}(\%)=\frac{v_{\text {corr }}^{\mathrm{o}}-v_{\text {corr }}}{v_{\text {corr }}^{\mathrm{o}}} \times 100
$$

where $v_{\text {corr }}^{o}$ and $v_{\text {corr }}$ are the corrosion rates of mild steel in the absence and presence of capacitabine, respectively.

The results of weight loss method are shown in Table-1. The results showed that the capacitabine is a good corrosion inhibitor for mild steel in $1 \mathrm{M} \mathrm{HCl}$ solution. It has been found that the weight loss of the metal decreases as the concentration of the inhibitor in the corrosive medium increases, the rate of decrease of corrosion with concentration of inhibitor molecule may be attributed to the increase of surface coverage of metal by the inhibitor molecule.

Potentiodynamic polarization measurements: Polarization curves of mild steel in $1 \mathrm{M} \mathrm{HCl}$ are given Fig. 1. Electrochemical corrosion kinetic parameters obtained are shown in Table- 2 . In $1 \mathrm{M} \mathrm{HCl}$ (i.e. acidic solution), the anodic corrosion reaction is the oxidation of metal to give $\mathrm{M}^{\mathrm{nt}}$ whereas at cathodic corrosion reaction is reduction of $\mathrm{H}^{+}$ions to produce $\mathrm{H}_{2}$ gas or reduction of $\mathrm{O}_{2}$. The inhibition may affect both or any of the above said reaction. From Table-2, it is clear that $\mathrm{I}_{\text {corr }}$ decreases as the concentration of inhibitor increases and it may be due to increase of surface coverage of metal surface by inhibitor. The $\mathrm{I}_{\text {corr }}$ values
TABLE-1

CORROSION PARAMETERS OBTAINED FROM

WEIGHT LOSS MEASUREMENTS FOR MILD STEEL IN 1M HCl SOLUTION AT $298 \mathrm{~K}$

\begin{tabular}{ccc}
\hline $\begin{array}{c}\text { Corrosive medium of } \\
\text { capacitabine }(\mathrm{ppm})\end{array}$ & $\begin{array}{c}\text { Corrosion rate }(\rho) \\
(\mathrm{mpy})\end{array}$ & $\begin{array}{c}\text { Inhibition efficiency } \\
\left(\% \eta_{\mathrm{w}}\right)\end{array}$ \\
\hline Blank & 0.030 & - \\
10 & 0.024 & 20.00 \\
20 & 0.020 & 33.33 \\
30 & 0.018 & 40.00 \\
40 & 0.013 & 56.66 \\
50 & 0.010 & 66.66 \\
\hline
\end{tabular}

decrease steadily from the blank value with increase in inhibitor concentration. This decrease in $\mathrm{I}_{\text {corr }}$ is an indication of decrease in corrosion reaction, since corrosion current is proportional to the magnitude of corrosion reaction. The $\beta_{\mathrm{a}}$ and $\beta_{\mathrm{c}}$ values change upon addition of the inhibitor from the blank, which means the extract molecules are adsorbed both on anodic and cathodic sites. This results in the inhibition of both anodic metal dissolution and cathodic reduction reactions of hydrogen ion of acid. It means that inhibitor efficiency increases with concentration. It can be interpreted as capacitabine molecules retard the corrosion reaction. So, it can be concluded that the capacitabine acts as mixed type inhibitor i.e. it inhibits both anodic and cathodic reactions.

Electrochemical impedance spectroscopic (EIS) measurements: Corrosion study of mild steel in $1 \mathrm{M} \mathrm{HCl}$ with and without capacitabine is studied by using electrochemical impedance spectroscopy. Fig. 2 shows a Nyquist plot for mild steel in $1 \mathrm{M} \mathrm{HCl}$ solution. Thus Fig. 2 suggest that the impedance behaviour changed by the addition of inhibitor molecules to $1 \mathrm{M}$ $\mathrm{HCl}$ media. The data are given in Table-2. The impedance spectra exhibited a single semicircle for a particular concentration, and the diameter of semicircle increases with increase in inhibitor concentration, which is due to increase in charge transfer reaction and hence the corrosion inhibition. The single semicircle indicates that the charge transfer takes place at electrode/solution interface and the corrosion reaction of mild steel is controlled by the charge transfer process. The capacitive loops are not perfect semicircle; this can be due to frequency dispersion and asymmetry in mild steel sample surface. As the inhibitor concentration increases double layer capacitance $\left(\mathrm{C}_{\mathrm{dl}}\right)$ value decreases, which confirms the increased level of adsorption of the inhibitor on the metal surface and the value of $R_{c t}$ value increases, from the blank value. This indicates the resistance toward charge transfer reactions responsible for corrosion process. These observations clearly prove the dependence of inhibitor concentration on corrosion control. The impedance spectra for Nyquist plots were analyzed by fitting to the equivalent circuit model.

The inhibition efficiency obtained from weight loss and electrochemical measurements are in good agreement at all concentrations. This indicates capacitabine is a good corrosion inhibitor on mild steel in $1 \mathrm{M} \mathrm{HCl}$.

As $R_{c t}$ is inversely proportioned to the corrosion current density, it was used to determine the inhibition efficiency (I.E.) $(\eta, \%)$ from the relationship:

$$
\eta_{\mathrm{z}}(\%)=\frac{\mathrm{R}_{\mathrm{ct}}-\mathrm{R}_{\mathrm{ct}}^{\mathrm{o}}}{\mathrm{R}_{\mathrm{ct}}} \times 100
$$




\begin{tabular}{|c|c|c|c|c|c|c|c|c|c|c|c|}
\hline \multicolumn{12}{|c|}{$\begin{array}{l}\text { TABLE-2 } \\
\text { POLARIZATION PARAMETERS AND EIS PARAMETERS FOR MILD STEEL IN } 1 \mathrm{M} \text { HCI AT DIFFERENT } \\
\text { TEMPERATURE IN PRESENCE OF VARIOUS CONCENTRATIONS OF CAPACITABINE }\end{array}$} \\
\hline $\begin{array}{l}\text { Temp. } \\
\text { (K) }\end{array}$ & $\begin{array}{l}\text { Inh. conc. } \\
\text { (pmM) }\end{array}$ & $\begin{array}{l}\mathrm{E}_{\text {corr }} \\
\text { (V) }\end{array}$ & $\begin{array}{c}\mathrm{i}_{\text {corr }} \\
\left(\mathrm{A} \mathrm{cm}^{-2}\right)\end{array}$ & $\begin{array}{c}v_{\text {corr }} \\
(\mathrm{mpy})\end{array}$ & $\begin{array}{c}\beta c \\
(\mathrm{mv} / \mathrm{dec})\end{array}$ & $\begin{array}{c}\beta \mathrm{a} \\
(\mathrm{mv} / \mathrm{dec})\end{array}$ & $\begin{array}{l}\eta_{\mathrm{p}} \\
(\%)\end{array}$ & $\begin{array}{c}\mathrm{R}_{\mathrm{ct}} \\
\left(\Omega \mathrm{cm}^{2}\right)\end{array}$ & $\begin{array}{c}\mathrm{C}_{\mathrm{dl}} \\
\left(\mathrm{F} \mathrm{cm}^{-2}\right)\end{array}$ & $\begin{array}{l}\eta_{\mathrm{z}} \\
(\%)\end{array}$ & $(\Theta)$ \\
\hline \multirow{6}{*}{298} & Blank & -0.482 & 0.0693 & 20.82 & -6.622 & 11.717 & - & 151.4 & 0.0156 & - & - \\
\hline & 10 & -0.474 & 0.0556 & 13.43 & -7.003 & 12.494 & 19.76 & 215.8 & 0.0150 & 29.84 & 0.298 \\
\hline & 20 & -0.482 & 0.0428 & 13.37 & -6.984 & 13.481 & 38.23 & 304.7 & 0.0128 & 50.31 & 0.503 \\
\hline & 30 & -0.478 & 0.0349 & 10.78 & -6.788 & 13.510 & 49.63 & 384.0 & 0.0139 & 60.57 & 0.605 \\
\hline & 40 & -0.485 & 0.0292 & 8.30 & -6.927 & 11.323 & 57.86 & 448.7 & 0.0121 & 66.25 & 0.662 \\
\hline & 50 & -0.489 & 0.0187 & 6.77 & -6.786 & 11.545 & 73.01 & 627.6 & 0.0118 & 75.87 & 0.758 \\
\hline \multirow{6}{*}{308} & Blank & -0.477 & 0.0815 & 26.02 & -7.242 & 11.884 & - & 63.76 & 0.0161 & - & - \\
\hline & 10 & -0.483 & 0.0615 & 19.13 & -7.235 & 11.883 & 24.53 & 85.41 & 0.0155 & 25.34 & 0.253 \\
\hline & 20 & -0.481 & 0.0581 & 15.80 & -6.872 & 12.354 & 33.76 & 95.63 & 0.0153 & 33.32 & 0.333 \\
\hline & 30 & -0.475 & 0.0456 & 12.70 & -7.088 & 12.345 & 44.04 & 130.3 & 0.0143 & 51.06 & 0.510 \\
\hline & 40 & -0.477 & 0.0365 & 11.27 & -6.871 & 13.066 & 55.21 & 136.2 & 0.0139 & 53.23 & 0.532 \\
\hline & 50 & -0.473 & 0.0268 & 8.83 & -7.856 & 13.335 & 67.11 & 143.3 & 0.0129 & 58.31 & 0.583 \\
\hline \multirow{6}{*}{318} & Blank & -0.471 & 0.1110 & 21.67 & -6.300 & 11.728 & - & 56.26 & 0.0158 & - & - \\
\hline & 10 & -0.478 & 0.0768 & 14.90 & -7.174 & 11.908 & 30.81 & 74.34 & 0.0155 & 24.32 & 0.243 \\
\hline & 20 & -0.473 & 0.0700 & 13.57 & -6.753 & 12.035 & 36.93 & 92.3 & 0.0154 & 39.51 & 0.395 \\
\hline & 30 & -0.475 & 0.0505 & 9.79 & -6.568 & 11.944 & 54.50 & 97.6 & 0.0156 & 42.35 & 0.423 \\
\hline & 40 & -0.482 & 0.0476 & 9.22 & -6.657 & 11.582 & 57.11 & 114.9 & 0.0140 & 51.03 & 0.510 \\
\hline & 50 & -0.481 & 0.0398 & 7.72 & -6.895 & 12.206 & 64.14 & 141.1 & 0.0134 & 60.12 & 0.601 \\
\hline \multirow{6}{*}{328} & Blank & -0.471 & 0.1400 & 27.14 & -6.152 & 12.109 & - & 43.31 & 0.0159 & - & - \\
\hline & 10 & -0.477 & 0.1110 & 20.31 & -6.809 & 11.465 & 25.71 & 55.85 & 0.0160 & 22.45 & 0.224 \\
\hline & 20 & -0.484 & 0.0940 & 18.23 & -6.610 & 10.643 & 32.85 & 66.68 & 0.0153 & 35.04 & 0.350 \\
\hline & 30 & -0.478 & 0.0791 & 15.35 & -6.632 & 11.292 & 43.50 & 74.85 & 0.0160 & 42.13 & 0.421 \\
\hline & 40 & -0.485 & 0.0646 & 12.52 & -7.721 & 10.803 & 53.85 & 84.68 & 0.0199 & 48.85 & 0.488 \\
\hline & 50 & -0.486 & 0.0585 & 11.34 & -6.886 & 11.195 & 58.21 & 94.93 & 0.0152 & 54.37 & 0.543 \\
\hline
\end{tabular}
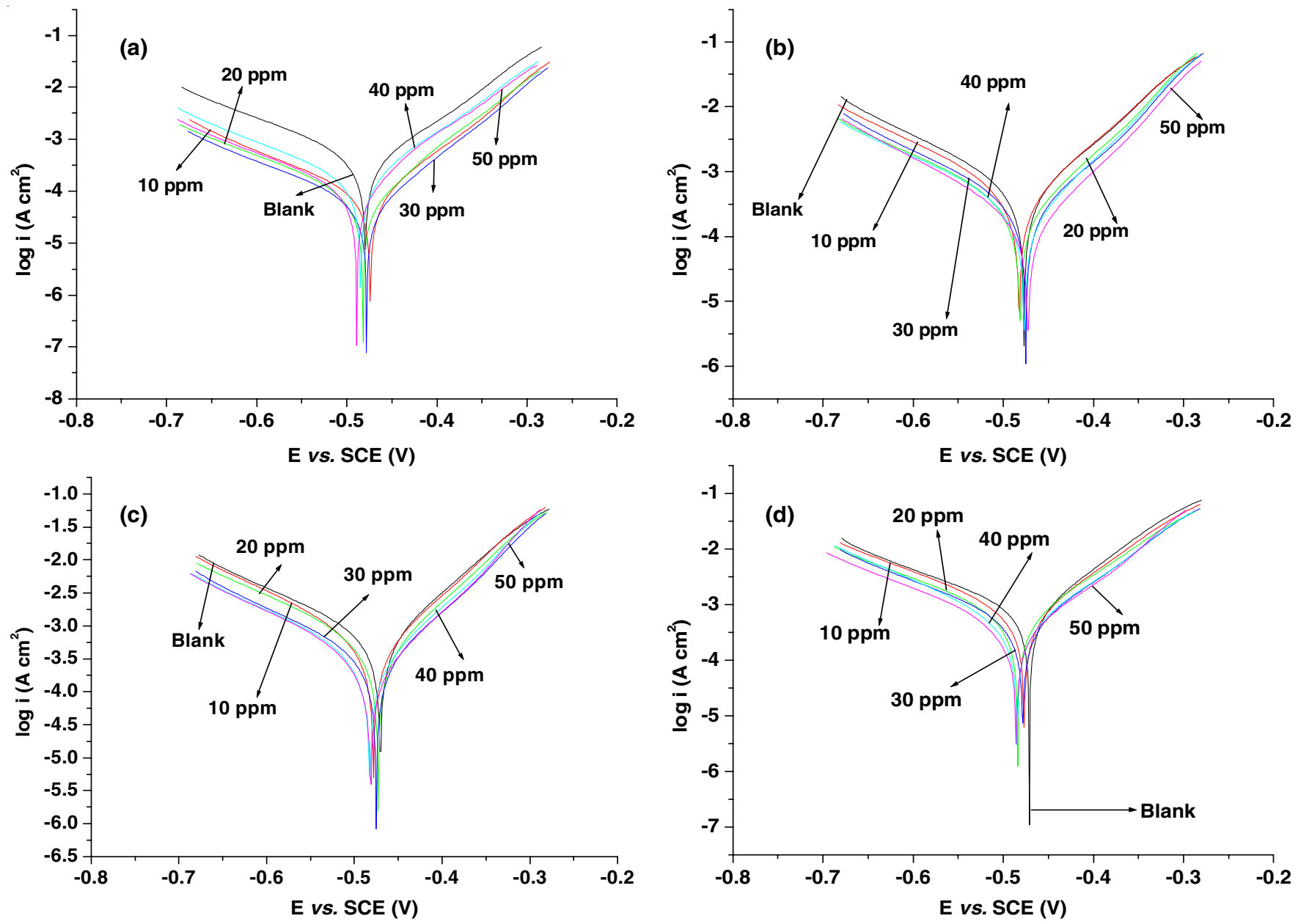

Fig. 1. Tafel plots for mild steel in $1 \mathrm{M} \mathrm{HCl}$ in the absence and presence of different inhibitor concentrations at $298 \mathrm{~K}$ (a) $308 \mathrm{~K}$ (b) $318 \mathrm{~K}$ (c) and $328 \mathrm{~K}(\mathrm{~d})$ 

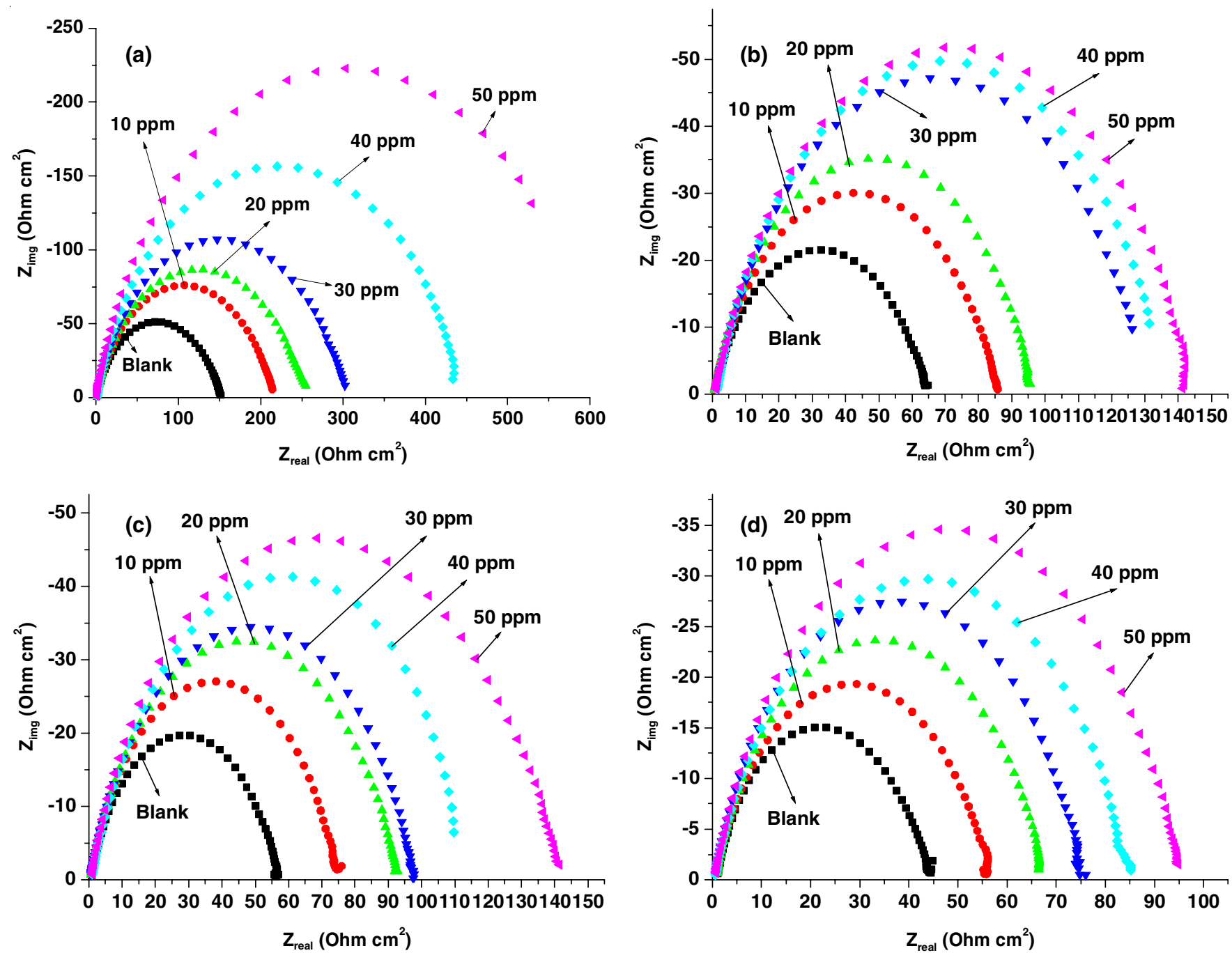

Fig. 2. Nyquist plots for mild steel in $1 \mathrm{M} \mathrm{HCl}$ in the absence and presence of different inhibitor concentrations $298 \mathrm{~K}$ (a) $308 \mathrm{~K}$ (b) $318 \mathrm{~K}$ (c) and $328 \mathrm{~K}(\mathrm{~d})$

where $R_{c t}$ and $R_{c t}^{\circ}$ are polarization resistance value in presence and absence of inhibitor, respectively.

The double layer capacitance $\left(\mathrm{C}_{\mathrm{dl}}\right)$ value can be calculated by using following equation:

$$
\mathrm{C}_{\mathrm{dl}}=\left(\mathrm{QR}_{\mathrm{ct}}^{1-\mathrm{n}}\right)^{1 / \mathrm{n}}
$$

where $\mathrm{Q}=$ constant phase element $(\mathrm{CPE})\left(\Omega^{-1} \mathrm{~S}^{\mathrm{n}} \mathrm{cm}^{-2}\right), \mathrm{n}=$ $\mathrm{CPE}$ exponent, which provide the information about surface in homogeneity.

Adsorption isotherm studies: The adsorption of an organic adsorbate on to metal-solution interface can be represented by a substitutional adsorption process between the organic molecules in the aqueous solution phase and the water molecules on the metallic surface. Basic information on the interaction between the inhibitor and the mild steel surface can be provided by the adsorption isotherm [25]. For this purpose, the values of surface coverage $(\theta)$ at different concentrations $(C)$ of capacitabine in acidic media in the temperature range (298-328 K) have been used to explain the best isotherm to determine the adsorption process. Attempts were made to fit these $\theta$ values to various isotherm including Freundlich, Langmuir, Temkin. The best fit was obtained with Langmuir isotherm as shown in Fig. 3. The inhibition efficiency afforded by the inhibitor

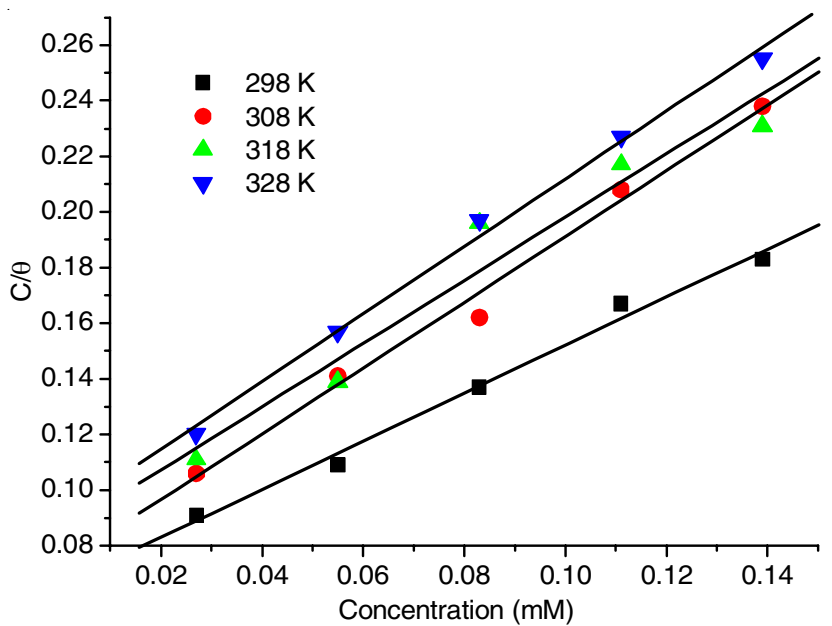

Fig. 3. Langmuir adsorption isotherm

molecules to mild steel due to the presence of electron rich $\mathrm{O}$, $\mathrm{N}$ and aromatic rings. The adsorption of the inhibitor molecules on the mild steel surface can be explained on the basis of the donor acceptor interaction between electrons of donor atoms $\mathrm{N}$ and aromatic rings of the inhibitors and the vacant $d$ orbitals of iron surface atoms. 


\section{Conclusion}

In view of above results, one can concluded that the capacitabine, a water soluble anticancer drug, acts as a good corrosion inhibitor for mild steel in $\mathrm{HCl}$ media. Polarization studies showed that the capacitabine acts as mixed type corrosion inhibitor and the inhibitor efficiencies obtained by weight loss, polarization and AC impedance are all comparable with one another. Inhibitor efficiency increased with increase in the concentration of capacitabine with the maximum inhibitor efficiency in and around $70 \%$ for a concentration of $50 \mathrm{ppm}$ and finally the adsorption of capacitabine on mild steel surface from $\mathrm{HCl}$ solution (1 M) obeyed Langmuir's adsorption isotherm.

\section{REFERENCES}

1. J. Liu, W. Yu, J. Zhang, S. Hu, L. You and G. Qjao, Appl. Surf. Sci., 256, 4729 (2010);

https://doi.org/10.1016/j.apsusc.2010.02.082.

2. S.K. Shukla, M. A. Quraishi, R. Prakash, Corros. Sci., 50, 2867 (2008); https://doi.org/10.1016/j.corsci.2008.07.025.

3. H.S. Gadow and M.M. Motawea. RSC Adv., 7, 24576 (2017); https://doi.org/10.1039/C6RA28636D.

4. A.K. Singh, S.K. Shukla, M. Singh and M.A. Quraishi, Mater Chem. Phys., 129, 68 (2011); https://doi.org/10.1016/j.matchemphys.2011.03.054.

5. S.K. Shukla and M.A. Quraishi. Mater. Chem. Phys., 120, 142 (2010); https://doi.org/10.1016/j.matchemphys.2009.10.037.

6. L. Paul and R.L. Machunda. J. Miner. Mater. Charact. Eng., 4, 33 (2016); https://doi.org/10.4236/jmmce.2016.41004.

7. H. Ma, T. Song, H. Sun and X. Li, Thin Solid Films, 516, 1020 (2008); https://doi.org/10.1016/j.tsf.2007.06.225.

8. M. Tourabi, K. Nohair, M. Traisnel, C. Jama and F. Bentiss, Corros. Sci., 75, 123 (2013); https://doi.org/10.1016/j.corsci.2013.05.023.

9. A. Kosari, M. Momeni, R. Parvizi, M. Zakeri, M.H. Moayed, A. Davoodi and H. Eshghi, Corros. Sci., 53, 3058 (2011); https://doi.org/10.1016/j.corsci.2011.05.009.
10. A.O. Yuce, R. Solmaz and G. Kardas, Mater. Chem. Phys., 131, 615 (2012); https://doi.org/10.1016/j.matchemphys.2011.10.026.

11. I.B. Obot, N.O. Obi-Egbedi and S.A. Umoren, Corros. Sci., 51, 1868 (2009); https://doi.org/10.1016/j.corsci.2009.05.017.

12. H.P. Sachin, B.M. Praveen and S.B. Abd Hamid, Res. J. Chem. Sci., 3, 82 (2013).

13. S.H. Kumar and S. Karthikeyan, J. Mater. Environ. Sci., 3, 925 (2012).

14. X. Zheng, M. Gong and Q. Li, Int. J. Electrochem. Sci., 12, 6232 (2017).

15. A.M. Al-Fakih, M. Aziz and H.M. Sirat. J. Mater. Environ. Sci., 6, 1480 (2015).

16. K.F. Al-Azawi, S.B. Al-Baghdadi, A.Z. Mohamed, A.A. Al-Amiery, T.K. Abed, S.A. Mohammed, A.A.H. Kadhum and A.B. Mohamad, Chem. Cent. J., 10, 23 (2016); https://doi.org/10.1186/s13065-016-0170-3.

17. W.-H. Li, Q. He, S.-T. Zhang, C.-L. Pei and B.-R. Hou. J. Appl. Electrochem., 38, 289 (2008); https://doi.org/10.1007/s10800-007-9437-7.

18. R.S. Abdel Hameed, H.I. Al-Shafey and A.H. Abu Nawwas. Int. J. Electrochem. Sci., 9, 6006 (2014).

19. R.A. Prabhu, T.V. Venkatesha, A.V. Shanbhag, G.M. Kulkarni and R.G. Kalkhambar, Mater. Chem. Phys., 108, 283 (2008); https://doi.org/10.1016/j.matchemphys.2007.09.038.

20. S.M.A. Hosseini and A. Azimi, Corros. Sci., 51, 728 (2009); https://doi.org/10.1016/j.corsci.2008.11.019.

21. M.K Pavithra, T.V Venkatesha, M.K Puneeth Kumar and H.C Tandon, Corros. Sci., 60, 104 (2012); https://doi.org/10.1016/j.corsci.2012.04.003.

22. H. Ashassi-Sorkhabi, B. Shaabani and D. Seifzadeh, Electrochim. Acta, 50, 3446 (2005); https://doi.org/10.1016/j.electacta.2004.12.019.

23. O. Olivares-Xometl, N.V. Likhanova, M.A. Domínguez-Aguilar, J.M. Hallen, L.S. Zamudio and E. Arce, Appl. Surf. Sci., 252, 2139 (2006); https://doi.org/10.1016/j.apsusc.2005.03.178.

24. A.M. Al-Fakih, M. Aziz, H.H. Abdallah, Z.Y. Algamal, M.H. Lee and H. Maarof, Int. J. Electrochem. Sci., 10, 3568 (2015).

25. A. Khamis, M.M. Saleh and M.I. Awad, Int. J. Electrochem. Sci., 7, 10487 (2012). 